\title{
A GESTÃO DE CONTRATOS E SUA INFLUÊNCIA NA QUALIDADE DO PROCESSO DE PROJETO: ESTUDO DE CASO EM CONSTRUTORAS DO RIO DE JANEIRO
}

\author{
Valéria N. S. CAIADO \\ Arquiteta, Mestre em Arquitetura, Diretora da \\ Construtora Caiado - vcaiado@hotmail.com \\ Mônica S. SALGADO \\ Arquiteta, Mestre em Arquitetura, Doutora em \\ Engenharia de Produção, Professora da Universidade \\ Federal do Rio de Janeiro - monicassalgado@ufri.br
}

\begin{abstract}
RESUMO
A qualidade do projeto de arquitetura tem sido foco de estudo de diversos pesquisadores. Observa-se que, de maneira geral, grande parte dos problemas técnicos encontrados na fase de uso-ocupação das edificações relaciona-se com erros durante a compatibilização dos projetos, falta de integração dos projetistas com a obra, e falta de integração entre os profissionais de projeto, para citar alguns problemas. Não raro estes fatores são abordados apenas na etapa póscontratação, sendo ignorado que a forma e tipo de contrato celebrado entre o construtor e o projetista são responsáveis pela definição das inter-relações entre a equipe de projeto e a obra, estabelecendo de que forma e com que freqüência serão realizadas as visitas à obra, definindo o grau de detalhamento do projeto, entre outros aspectos. Com o objetivo de identificar de que forma os contratantes construtores estão encarando esse importante determinante das relações entre os agentes da cadeia da construção civil, foram ouvidas empresas cariocas certificadas pela ISO 9001/2000. Essa pesquisa mostrou os aspectos mais usuais das formas de contratação dos profissionais de projeto, a influência destas formas de contratação na qualidade do projeto e da construção, e as soluções adotadas pelas construtoras, em função de suas próprias experiências, na busca de um sistema de contratação que pudesse garantir a qualidade do processo de projeto. Os resultados indicam que a contratação de projetistas ainda é um gargalo na gestão do processo do projeto, e que os modelos adotados pelas empresas construtoras nem sempre isentam da ocorrência de problemas que podem gerar, em última análise, aumento nos custos e formação de imagem negativa junto aos clientes.
\end{abstract}

Palavras-Chaves: formas de contratação, qualidade do projeto, contratos

\begin{abstract}
The quality of architectural design has been studied by many researchers. Part of technical problems observed during the post-occupancy phase of the buildings is frequently related with design management failures. It is important to understand that the form and type of contract celebrated between the constructor and the architect is responsible for the definition of the interrelations between the design team and the building constructor, establishing many aspects related with the project management as a hole. The aim of this paper is to identify most common elements in the architectural services contract, pointing out the contract aspects that affects directly the design development. A research with the Rio de Janeiro construction builders, with their quality management systems certified through ISO 9001/2000 rules, had been carried out. The results indicates that contracting is still a problem in architectural design management process, and that the models usually adopted by civil construction industry frequently contributes for technical faults that could be minimized with the adoption of basic principles which could reduce the occurrence of problems and, consequently, could reduce the costs.
\end{abstract}

Key words: design process, architectural contract 


\section{INTRODUÇÃO}

O projeto tem sido avaliado em diversas pesquisas como sendo o maior responsável pela falta de qualidade na construção civil. Pesquisas indicam que, em média, $42 \%$ dos defeitos detectados na construção são decorridos de decisões ou ações tomadas ao longo do desenvolvimento do projeto. As causas da falta de qualidade nos projetos arquitetônicos têm sido bastante debatidas e estudadas nos últimos anos, observando-se certa repetição nos problemas identificados, como a falta de integração entre os projetistas e a escassez de visitas à obra por parte do arquiteto.

Melhado e Aquino (2001) lista outras dificuldades encontradas durante o desenvolvimento do projeto tais como: incapacidade e desinteresse de muitos projetistas, que concebem o produto sem que haja preocupação com o processo de produção, construtibilidade e manutenibilidade nas soluções adotadas; indefinição de responsabilidades; na fase de entrega dos projetos, eles simplesmente "vão chegando" à medida que a obra está sendo executada, não existindo procedimentos corretos para a sua entrega; na fase de desenvolvimento do projeto "as built" percebe-se o aumento de custos por não se ter previsto as modificações de projeto anteriormente.

Os problemas detectados acima, indicam algumas causas para a falta de qualidade nos projetos arquitetônicos, mas não definem por que elas ocorrem. Normalmente as discussões restringem-se aos aspectos relacionados com a compatibilização de projetos, realização de projetos para produção e maior ligação projetista/obra. Entretanto sem um sistema de contratação que possa garantir as condições de trabalho adequadas à realização do projeto, será impossível sanar os problemas identificados.

A experiência das construtoras que atuam no mercado imobiliário da cidade do Rio de Janeiro demonstra que parte dos problemas que ocorrem durante a realização da obra - e que são atribuídos aos projetos - pode ser sanada (ou ao menos reduzida) a partir da utilização do contrato não apenas como instrumento legal, mas como verdadeiro definidor das relações de trabalho entre as partes.

Esta discussão é bastante ampla na medida em que o tipo de contratação dos serviços de arquitetura varia conforme o porte do empreendimento, o tipo de edificação, o tipo de cliente e, naturalmente, o uso pretendido para o empreendimento a ser projetado, para citar apenas algumas das inúmeras questões envolvidas neste processo. Daí a importância de se tratar a questão do contrato dos projetos de arquitetura de forma cuidadosa, buscando a identificar quais falhas atribuídas ao projeto não teriam, na verdade, ocorrido em conseqüência de um sistema de contratação inadequado.

\section{O CONTRATO COMO INTERVENIENTE PARA A GESTÃO DA QUALIDADE}

De acordo com Castells e Heineck (2001), na maioria dos estudos do processo de projeto não é aprofundado o tema sobre procedimentos e métodos de projetação aplicados pelos arquitetos durante o processo de elaboração do projeto. Para a elaboração do projeto é estabelecido um programa de necessidades, que leva em 
consideração as condições apresentadas pelo contratante, incorporador, legislação, usuário, ou por mais de um destes agentes, e pelas especificidades do próprio local destinado a construção da edificação.

O programa de necessidades tem a função de identificar aspectos relacionados com a realização do empreendimento, que não podem deixar de ser levados em consideração pelo arquiteto. Algumas vezes, essa identificação é feita pelo próprio arquiteto contratado, que analisará as limitações e benefícios para a implantação da edificação, e tomará as decisões que melhor atendam às necessidades estabelecidas.

Normalmente, ao se celebrar um contrato para o desenvolvimento de um projeto de arquitetura, uma vez definidas as fases e responsabilidades incluídas naquele contrato (desenvolvimento desde o estudo preliminar ou apenas o projeto de execução) é estabelecido um preço, um prazo, um número mínimo de plantas a serem executadas pelo arquiteto e as obrigações e responsabilidade deste, dentro do processo de produção do empreendimento. Entretanto, entende-se que este contrato deva ser feito com clareza e calma, para que estes prazos e valores não comprometam as etapas de projeto, que necessitam de tempo para que as idéias e opções de partidos sejam analisadas.

As formas de contratação dos serviços de arquitetura foram definidas pela ASBEA (2000), e são relacionadas a seguir:

Convite direto: Pode ser feito por um cliente particular, por indicação ou confiança. No caso de um cliente público, só poderá contratar por convite direto até um determinado valor previsto por lei. Neste caso, normalmente existe uma relação de confiança entre as partes, podendo ocorrer deficiência no tipo de contrato que será firmado.

Seleção Restrita: Representa a segunda forma direta de contratação, sendo que o cliente pré-seleciona um número restrito de escritórios de acordo com a experiência de cada um, procedendo a seguir entrevistas com seus titulares e visitas à empresa, trabalhos executados, verifica disponibilidade de pessoal para cumprir prazo de tarefa, etc. Após as entrevistas, e conforme o atendimento aos requisitos estabelecidos, o contratante seleciona o escritório.

Existe também a opção do contratante escolher um escritório para cada fase do projeto, contratando o arquiteto antes mesmo da contratação da equipe responsável pela obra. Ressalte-se que este tipo de contratação pode não garantir a qualidade do produto final, pois fere o princípio da simultaneidade na participação de todos os intervenientes no processo de construção.

Apresentação de Propostas Técnicas em Seleção Restrita: Como na forma anterior, dentro de um número restrito de escritórios, é solicitada a elaboração de proposta técnica para a metodologia de trabalho e conceito teórico do projeto a ser executado. Nesta modalidade, antes da escolha dos profissionais que executarão o projeto, existe pré-definido um programa de necessidades, para que os participantes da seleção possam demonstrar sua habilidade técnica. O contrato é o definidor das propostas, pois nele estarão descritas todas as responsabilidades e obrigações do contratado, sendo que este último poderá demonstrar a melhor metodologia de trabalho, não sendo mais obrigatoriamente as percepções do contratante. A qualidade do sistema de trabalho e as relações entre os agentes do processo irão contribuir para maior qualidade do produto final, embora a escolha da melhor técnica e metodologia ainda seja feita pelo contratante. 
Licitações: Feitas pelo poder público de acordo com a LEI 8666/93, que estabelece normas gerais sobre licitações e contratos administrativos pertinentes a obras, serviços (inclusive de publicidade), compras, alienações e locações no âmbito dos Poderes da União, dos Estados, do Distrito Federal e dos Municípios, onde estão previstas as modalidades de licitações: concorrência, tomada de preços, convite, concurso e leilão, podendo ser do tipo de Menor Preço, Melhor Técnica ou Melhor Técnica e Preço.

Muitas vezes, as licitações são feitas com os projetos separadamente, ou seja, o projeto de arquitetura é licitado primeiro, depois da realização deste é licitado o projeto de estruturas, seguido pelo projeto das instalações prediais e assim sucessivamente, causando a total fragmentação do processo de projeto. Em outras situações, o projeto é visto de forma global, fazendo-se a licitação da totalidade de projetos, Cabe destacar que, de acordo com esta lei, o responsável pelo desenvolvimento do projeto não poderá participar da licitação para execução da obra.

Concursos: Os concursos podem ser públicos ou privados e consistem na escolha do melhor candidato para a elaboração do projeto a ser executado, sendo aberto a todos os profissionais legalmente habilitados. Os concursos poderão ter mais de uma fase, permitindo uma seleção de projetos finalistas.

De acordo com a ASBEA (2000), os concursos como forma de contratação só podem ser admitidos desde que o trabalho profissional desenvolvido seja plenamente remunerado para todos os participantes. Os concursos privados são normalmente organizados pelas próprias empresas, que convidam alguns escritórios de arquitetura a participarem do mesmo, podendo ser considerado como uma seleção restrita. Ainda de acordo com a ASBEA (2000), os concursos públicos somente se justificam em casos excepcionais, onde se apresente a necessidade de debate dos assuntos de interesse público pela classe dos arquitetos.

Cadastro de Escritórios: O cadastramento prévio é definido por uma série de determinações legais, técnicas e financeiras, através da apresentação de diversos documentos em tudo semelhante ao das licitações e também regido pela LEI 8666/93. Quando da oportunidade de contratação, o órgão escolhe de acordo com o porte e experiência profissional, o escritório que mais se enquadra com o projeto a ser executado.

Diante do exposto percebe-se que o contrato interfere diretamente nas decisões arquitetônicas e, portanto, na qualidade do projeto. Até mesmo o projeto contratado por licitação possui diversos itens que deverão ser considerados durante a realização do mesmo.

Ao se referir aos procedimentos para transformar os requerimentos de programa, que são as premissas lançadas pelo contratante, num esquema, e a partir deste, a evolução da idéia até o anteprojeto, percebe-se que o projeto já começou antes mesmo dele ser concebido, pensado e representado pelos projetistas. O projeto começa já durante a definição do programa de necessidades. Este irá definir grande parte das soluções traçadas e interferirá na qualidade do projeto, pois as soluções resultantes nesta etapa serão as metas do empreendimento, qualificando o tipo de projeto e as premissas básicas para o desenvolvimento do produto final. De forma geral, falta aos profissionais envolvidos na cadeia de produção da edificação, a visão geral do empreendimento, tendo o foco orientado ao cliente final. $\mathrm{Na}$ visão 
de Lana e Andery (2001), prevalece entre esses profissionais uma mentalidade contratual, caracterizada por uma contínua negociação a respeito de obrigações e responsabilidades. Isso implica que o processo seja segmentado, e as soluções ao longo da cadeia, desde as etapas iniciais, vão "trocando de mãos".

O contrato existe para definir os parâmetros das relações entre as partes envolvidas, mas a forma como estas relações irão se estabelecer, serão definidas pelo contratante. Muitos estudos apontam a necessidade de integração entre todos os projetistas envolvidos num empreendimento, mas isso somente ocorrerá se estes projetistas forem contratados de forma coordenada, visando a garantir a divulgação das decisões de projeto entre todos os profissionais envolvidos com o desenvolvimento do mesmo. Diante destes fatos, percebe-se a importância do contrato na gestão da qualidade do processo do projeto arquitetônico e, conseqüentemente, na qualidade da construção civil.

A definição de qualidade como adequação a determinados requisitos é aquela que melhor expressa o movimento que, na construção civil, ganhou maior impulso na década de 90, quando as empresas entenderam que deveriam buscar caminhos para incorporar novos conceitos de gerenciamento da produção às suas práticas diárias. $\mathrm{O}$ foco dos trabalhos concentrou-se nas questões ligadas especificamente à execução da obra e as construtoras iniciaram um trabalho que incluiu (Salgado, 2004):

- a divulgação e adoção das normas de especificação e controle da qualidade no recebimento dos materiais de construção;

- a definição dos procedimentos operacionais e de execução de serviços praticados nas obras;

- a sensibilização e treinamento da mão-de-obra sobre os processos padronizados.

Naquele momento, portanto, as questões relacionadas com o desenvolvimento do projeto do edifício ainda não haviam sido consideradas.

A importância do tema para o País levou à instituição, pelo Governo Federal, do PBQPh - Programa Brasileiro da Qualidade e Produtividade no Habitat. O objetivo geral do PBQP-h é apoiar o esforço brasileiro de modernidade pela promoção da qualidade e produtividade do setor da construção habitacional, com vistas a aumentar a competitividade de bens e serviços por ele produzidos, estimulando projetos que melhorem a qualidade do setor.

O Programa indicou a grande preocupação com a qualidade na produção do edifício, e foi também a partir dele que começou a ser fomentada a discussão das questões relacionadas com a gestão do processo do projeto, que ganharam destaque a partir de dois objetivos específicos definidos no Programa:

- fomentar o desenvolvimento e a implantação de instrumentos e mecanismos de garantia de qualidade de projetos e obras;

- promover a melhoria da qualidade de gestão nas diversas formas de projetos e obras habitacionais. 


\section{PESQUisa de CAMPO: LEVANTAMENTO dAS PRÁticas ADOTADAS NA GESTÃO DE CONTRATOS}

Com o objetivo de identificar as práticas adotadas pelas construtoras do Rio de Janeiro, especificamente em relação à contratação dos profissionais que participarão do desenvolvimento do projeto executivo de arquitetura, foi organizada uma pesquisa de campo junto às construtoras que possuem sistema da qualidade implantado e estão certificadas pela norma ISO 9001:2000 A opção por pesquisar nas empresas com sistema de qualidade implantado baseou-se no fato destas serem possuidoras de registros específicos sobre as formas de contratação dos prestadores de serviços, uma vez que este é um dos requisitos exigidos por esta norma.

Com base na pesquisa junto ao catálogo de empresas certificadas do CB-25, atualizado em março de 2004, identificaram-se oito empresas construtoras certificadas, sendo que apenas seis estavam enquadradas nos parâmetros desta pesquisa, ou seja, construtoras voltadas ao segmento de edifícios residenciais multifamiliares.

Foram contatadas as seis empresas construtoras, e marcadas entrevistas com os responsáveis pelo setor de projetos destas empresas e, em alguns casos, também com os engenheiros de obras. O questionário elaborado visou a salientar a importância da pesquisa e seu enfoque, permitindo que as empresas tecessem comentários livres, sem uma seqüência rígida. Foram feitas visitas às sedes das empresas e, em alguns casos, às suas obras, de forma a obter um amplo entendimento do funcionamento de cada setor. Embora não tenha existido um questionário fixo, foram apresentados alguns pontos básicos para que houvesse um parâmetro comum entre as entrevistas.

A primeira etapa da pesquisa consistiu em estabelecer as características de cada empresa analisada, que estão descritas no Quadro 1.

\begin{tabular}{|c|c|c|c|c|}
\hline CONSTRUTORA & $\begin{array}{c}\text { ANO DE } \\
\text { FUNDAÇÃO }\end{array}$ & $\begin{array}{c}\text { TIPOS DE } \\
\text { CONSTRUÇốES }\end{array}$ & $\begin{array}{c}\text { DESENVOLVIMENTO DE } \\
\text { PROJETOS }\end{array}$ & $\begin{array}{c}\text { ATUAÇÃO NO } \\
\text { MERCADO }\end{array}$ \\
\hline A & 1985 & $\begin{array}{c}\text { Residenciais e } \\
\text { Hospitalares }\end{array}$ & $\begin{array}{c}\text { Contratam todas as } \\
\text { etapas do projeto }\end{array}$ & $\begin{array}{c}\text { Construtora e } \\
\text { Incorporadora }\end{array}$ \\
\hline B & 1973 & Residenciais & $\begin{array}{c}\text { Contratam todas as } \\
\text { etapas do projeto }\end{array}$ & $\begin{array}{c}\text { Construtora e } \\
\text { Incorporadora }\end{array}$ \\
\hline C & 1976 & $\begin{array}{c}\text { Residenciais e } \\
\text { Comerciais }\end{array}$ & $\begin{array}{c}\text { Contratam todas as } \\
\text { etapas do projeto }\end{array}$ & $\begin{array}{c}\text { Construtora e } \\
\text { Incorporadora }\end{array}$ \\
\hline D & 1954 & Residenciais & $\begin{array}{c}\text { Contratam todas as } \\
\text { etapas do projeto }\end{array}$ & $\begin{array}{c}\text { Construtora e } \\
\text { Incorporadora }\end{array}$ \\
\hline E & 1994 & $\begin{array}{c}\text { Residenciais e } \\
\text { Comerciais }\end{array}$ & $\begin{array}{c}\text { Contratam todas as } \\
\text { etapas do projeto }\end{array}$ & $\begin{array}{c}\text { Construtora e } \\
\text { Incorporadora }\end{array}$ \\
\hline F & 1960 & Residenciais & $\begin{array}{c}\text { Contratam todas as } \\
\text { etapas do projeto }\end{array}$ & $\begin{array}{c}\text { Construtora e } \\
\text { Incorporadora }\end{array}$ \\
\hline
\end{tabular}

Quadro 1: Caracterização da Pesquisa de Campo

A segunda etapa da pesquisa consistiu em questionar a estruturação do setor de projetos de cada empresa, resgatando suas formas de contratação em todas as etapas de projetos. Para isso, foram apresentadas questões relativas aos seus respectivos processos construtivos, caracterizando as atividades executadas internamente e as que são efetivamente contratadas no setor de projetos, para que se pudesse obter um relato dos problemas enfrentados por cada empresa e as 
soluções encontradas, especificamente na etapa de contratação do projeto executivo, para alcançarem a garantia da qualidade dos seus empreendimentos.

\section{Empresa A}

Exerce as atividades de construtora e incorporadora. Quando atua como incorporadora dos seus empreendimentos, procura se associar com outras empresas a fim de obter parcerias nos investimentos. As empresas que se associam a empresa " $\mathrm{A}$ " para investir em seus empreendimentos costumam contratar outras empresas gerenciadoras para acompanhar todo o processo. De acordo com o entrevistado, que exerce a função de gerente de projetos da empresa, este fator influencia a contratação, pois existe a interferência dos sócios e das gerenciadoras nesta decisão. Como foi relatado por ele, estas gerenciadoras e empresas associadas nem sempre são as mesmas, o que causa uma variação de procedimentos para a contratação dos projetos, pois cada empresa associada possui formas e padrões diferenciados de condução de um empreendimento, sendo a empresa " $A$ " responsável por administrar a obra e os projetos contratados.

Também de acordo com a visão do gerente de projetos da empresa, estes procedimentos diferenciados geram imposições que não atendem de forma satisfatória a forma de contratação que é idealizada pelo setor, qualificando que a forma ideal de contratação dos projetistas seria fazer um cadastro de escritórios já conhecidos e trabalhar sempre com os mesmos profissionais, o que permitiria a possibilidade de se contratar o escritório que melhor se adequasse ao empreendimento em questão, trabalhando com valores de projeto pré-fixados que poderiam ser negociáveis ou não. Ele declara que teria menos problemas em relação aos projetos se a escolha dos profissionais fosse feita pelo setor de projetos da empresa, sem interferência das incorporadoras associadas.

Também conforme o entrevistado, quando a empresa é contratada por uma incorporadora para executar um empreendimento, não existe a necessidade de contratação de uma empresa gerenciadora dos projetos, cabendo à própria construtora executar este serviço, já que possui um setor de projetos dentro desta empresa. Nestes casos a empresa passaria a ter maior domínio das fases de projeto e de execução da obra, já que seriam gerenciados internamente, com autonomia para executar as contratações dos projetistas. Nestas condições, as contratações dos projetistas têm procedimentos diferentes para cada etapa do projeto: o arquiteto responsável pela realização do projeto legal e pela legalização deste nos órgãos competentes, em geral é o mesmo que fez o estudo de viabilidade que gerou a compra do terreno. Para os projetistas que desenvolvem os projetos executivos normalmente é feita uma concorrência, e são convidados 2 ou 3 escritórios de confiança da empresa para cada projeto. Ganha a concorrência o escritório que obtiver o menor preço. Estes escritórios de confiança foram caracterizados dentro de alguns indicadores de qualidade estabelecidos pela empresa no seu Sistema de Gestão da Qualidade, e que são confirmados pelo currículo apresentado por eles, e pela experiência de trabalhos anteriores realizados, considerados satisfatórios.

Os profissionais de arquitetura que desenvolvem o estudo de viabilidade para uma possível compra de um determinado terreno, não possuem contrato estabelecido e convivem ainda com a incerteza de sua continuidade dentro do processo construtivo. De acordo com o entrevistado, é comum que este arquiteto que conceituou o estudo de viabilidade e gerou a compra de um determinado 
terreno seja contratado para o desenvolvimento do projeto legal mas é somente após a autorização para o início do desenvolvimento do projeto legal que estes projetistas de arquitetura são efetivamente contratados. Caso não ocorra a compra do terreno, todo o trabalho do estudo de viabilidade é perdido, pois dentro da empresa não existe remuneração para esta etapa, sendo considerada como uma etapa de risco para o arquiteto que está tentando obter o serviço.

Nesta empresa os projetos são divididos em, no mínimo, duas etapas realizadas separadamente e por escritórios diferentes. De acordo com o gerente de projetos da empresa:

\footnotetext{
"um faz a concepção e o projeto legal, outro faz a execução e em alguns casos é contratado um terceiro escritório para fazer o que chamamos de "concepção visual", que engloba fachadas e definições das áreas comuns, principalmente de lazer e paisagismo. Atualmente temos casos em que a concepção inicial é feita por outra empresa, diferente da que faz o projeto legal." (gerente de projetos).
}

Na empresa "A", a coordenação de projetos é contratada no mesmo momento da contratação do projeto executivo, mas é preferencialmente feita por outra equipe de profissionais. A compatibilização dos projetos é feita pelo mesmo escritório responsável pelo projeto executivo, onde o coordenador faz uma verificação dos pontos críticos e mantém contato com as empresas ou profissionais contratados para elaborarem os projetos das especialidades.

\section{Empresa B}

Na empresa B, o processo é semelhante. A empresa possui um departamento de projetos que trabalha de duas formas distintas. Uma delas é escolhendo um terreno e fazendo um estudo de viabilidade com os profissionais de sua própria equipe de projetos, analisando a possibilidade econômica de investimento no local escolhido e, se aceito pelos sócios da empresa, contrata-se um escritório para a realização do projeto legal. A outra forma ocorre quando o terreno é oferecido à empresa por um escritório de arquitetura que já fez o estudo de viabilidade, e em alguns casos, já possui inclusive o projeto aprovado na Prefeitura do Rio de Janeiro, e o valor da compra do terreno já inclui o valor dos projetos executados. A contratação dos projetistas que irão dar continuidade a estes processos, tanto no primeiro caso, quanto no segundo, é feita a partir de uma seleção restrita de escritórios que já trabalham com a empresa e que foram cadastrados conforme a experiência profissional demonstrada junto à empresa. Alguns desses escritórios já trabalharam anteriormente com a empresa trazendo propostas de terrenos já com projetos desenvolvidos, tendo demonstrado eficiência em suas propostas. Outros escritórios são escolhidos por serem conhecidos no mercado imobiliário. $\mathrm{O}$ arquiteto contratado para executar o projeto legal é, normalmente, o mesmo que fez a concepção pois a empresa acredita que ao conceber um projeto o arquiteto precisa conhecer as leis e normas que recaem sobre o empreendimento, e a elaboração do projeto legal seria a continuidade natural desse processo, agilizando os procedimentos e otimizando o andamento do processo de projeto. Os prazos referentes às entregas das etapas do projeto são pré-estabelecidos pela construtora, já o preço que será pago por cada etapa do projeto é apresentado pelos escritórios que foram convidados a encaminhar propostas, sendo contratado o escritório que oferecer o menor valor. 
Ao se contratar o escritório responsável pela execução do estudo preliminar, o programa de necessidades é fornecido com as pré-determinações dos incorporadores e com os estudos feitos pela equipe de projeto da própria empresa, que determina alguns parâmetros que o empreendimento deve obedecer, como o número de unidades habitacionais, áreas comuns que farão parte do empreendimento, áreas de lazer, enfim, algumas exigências necessárias para gerar lucro. De acordo com o entrevistado, gerente de projetos da empresa, o arquiteto contratado tem liberdade para criar e decidir as características que o empreendimento irá possuir, inclusive modificando o programa de necessidades elaborado, juntamente com os incorporadores, desde que justifique as vantagens econômicas que a modificação trará para o negócio. Entretanto, entende-se que esta forma de contratação inibe e restringe as possibilidades reais de concepção e simulações de alternativas que poderiam ser adotadas para o empreendimento, pois não permite que o projetista participe da elaboração do programa de necessidades. O valor econômico e a necessidade de obtenção de lucro com o empreendimento são necessários e indiscutíveis, mas estes poderiam ser alcançados com o estudo mais detalhado do terreno e com a realização de simulações projetuais para a determinação do programa de necessidades mais satisfatório.

Para a realização do projeto executivo é contratado outro escritório de arquitetura, onde a forma de contratação segue os mesmos princípios das etapas anteriores, ou seja, também é contratado o escritório que apresentar o menor preço para a proposta. Os escritórios que são convidados a participar da concorrência são escolhidos entre aqueles que estão trabalhando no mercado, ou que já trabalharam para outras empresas e obtiveram um bom resultado. Os escritórios que participaram das outras etapas do processo de projeto podem participar da concorrência, mas o gerente de projetos desta empresa afirma que prefere que o projeto executivo seja efetuado por outra empresa, para que um mesmo projeto possa contar com a análise crítica de diferentes profissionais. Além disso, ele considera que já existe no mercado da construção civil, escritórios e profissionais que se especializaram em executar determinadas etapas do projeto, existindo maior experiência para o projeto de execução, outros para o projeto legal, etc. Sendo assim, geralmente são contatados os escritórios especializados para esta etapa. Os demais projetistas são contratados no mesmo momento do escritório responsável pelo projeto executivo, sendo que este último também tem a função de compatibilizar todos os projetos.

A coordenação dos projetos é atribuída ao escritório responsável pelo desenvolvimento do projeto executivo, sendo que este poderá ser substituído por outro, em alguns casos por exigência da incorporadora. Caso exista algum problema em relação à coordenação dos projetos, a equipe de profissionais da empresa construtora assume esta função pelo tempo necessário ou auxiliam e cobram as funções da empresa contratada.

De acordo com o entrevistado, existem problemas ocasionados por erros de projetos. Na opinião pessoal dele, esses erros ocorrem mais freqüentemente pelo problema da compatibilização dos projetos que não é feita dentro do tempo que seria efetivamente necessário para a realização do trabalho da forma devida, e, muitas vezes, os projetos acabam sendo encaminhados à obra incompletos, e as informações que ficaram faltando vão sendo inseridas aos poucos. 


\section{Empresa C}

Esta empresa tem como característica principal o fato de ser uma empresa familiar, tendo como administradores dois irmãos, e como engenheiros de obra, seus filhos. A empresa é sua própria incorporadora, só construindo com recursos próprios, e não possui setor de projetos dentro dela.

Em 1999 teve início o processo de certificação da empresa, que levou a uma grande mudança nos padrões gerais de execução de uma obra. De acordo com o entrevistado, gerente de obras da empresa, a etapa de projetos foi a que mais evoluiu, embora ainda não existisse à época dessa entrevista, um departamento próprio dentro da empresa. A empresa contrata um escritório de projetos que executa todas as etapas de projeto do empreendimento, desde o estudo de viabilidade, concepção inicial, interferência para a compra do terreno, estudo preliminar, projeto legal, projeto executivo e coordenação do projeto, sendo a compatibilização dos projetos feita pelo engenheiro de obras da empresa.

O entrevistado garante estar satisfeito com a contratação dos projetos sendo todas as etapas executadas pelo mesmo escritório, e os demais projetos - de estrutura e instalações - também são feitos sempre com os mesmos profissionais, pois ele acredita que a fidelidade em manter sempre os mesmos escritórios e profissionais contratados garante a maior facilidade das inter-relações entre estes profissionais e faz com que o preço de projeto tenha custo reduzido, visto que existe um "contrato de exclusividade fictício" entre as partes, passando a ser de interesse de todos os profissionais envolvidos na produção de qualquer empreendimento da empresa, que estes ocorram com a maior freqüência possível. O contrato de exclusividade é dito fictício porque esta exclusividade não existe de fato, todos os profissionais contratados podem exercer suas atividades para outras empresas construtoras, assim como já houve empreendimentos executados pela empresa em que o terreno já possuía projeto legal realizado por outro escritório de projeto. Neste caso, o projeto legal foi pago juntamente com o terreno, mas o projeto executivo foi elaborado pelo escritório que costuma fazer os projetos para a empresa.

Com o efetivo crescimento da empresa verificado nos últimos dois anos, o gerente de obras já vislumbra a possibilidade de se estabelecer um departamento de projetos dentro da própria empresa, com o intuito de fiscalizar e coordenar os serviços de projeto. Ele acredita que tudo tem ocorrido de forma eficiente, mas assegura que o processo ainda é muito centralizador, ficando a maioria das decisões por conta dele. Para que a empresa se desenvolva ainda mais, seria necessário desvincular os processos de construção da figura de uma única pessoa, adotando-se a mesma descentralização que já ocorre com a execução dos projetos. No momento desta entrevista estava se iniciando um novo empreendimento, que contava com a colaboração de um escritório de arquitetura que trabalharia com a empresa pela primeira vez e assumiria todas as etapas dos projetos, sendo, também, contratada outra equipe para efetuar a coordenação da obra.

Ao ser questionado sobre os motivos que levaram a empresa a se interessar pela implantação de um programa de qualidade e obtenção do certificado, o entrevistado relatou que essa foi a única forma encontrada de trabalhar de maneira coerente com os objetivos traçados para a empresa. Com a necessidade de atendimento aos requisitos da norma, eles tiveram que adotar instruções de trabalho que foram incorporadas à empresa. Atualmente os objetivos se voltam à 
otimização dos serviços com a periódica revisão dos procedimentos, visando ao aumento do lucro e rapidez na execução, com garantia de qualidade, e a contratação de pessoas capazes de agregar valores profissionais à empresa.

\section{Empresa D}

Esta empresa exerce as funções de construtora e incorporadora, sendo que estas duas atividades funcionam separadamente dentro da empresa, como se fossem firmas distintas, possuindo diretorias e atividades próprias, com a particularidade de sempre trabalharem conjuntamente. A incorporadora é sempre a avaliadora e financiadora dos empreendimentos da construtora. Dessa forma, todos os projetos dentro da construtora somente são realizados se a incorporadora concordar com os parâmetros adotados para estes. A incorporadora é, portanto, a responsável pela decisão de quais projetos serão realizados, dos custos que cada empreendimento poderá alcançar e dos terrenos que podem ser negociados. Ou seja, a incorporadora pode ser entendida como a "negociadora dos empreendimentos", cabendo à construtora seguir as determinações dadas.

A empresa trabalha de três formas distintas: comprando seus próprios terrenos, incorporando e construindo; aceitando um terreno de terceiros que queiram construir por sistema de permuta e que pode ou não já possuir projeto aprovado na Prefeitura do Rio de Janeiro; ou comprando um terreno que já possui projeto aprovado na Prefeitura do Rio de Janeiro.

Quando não existe projeto aprovado, a incorporadora contrata o projetista para execução do estudo de viabilidade para, então, avaliar as possibilidades econômicas de construção do empreendimento, ou seja, se este dará o lucro esperado e se existe interesse em executar a obra, verificando o local e as características gerais. Quando o terreno é comprado já com projeto legal aprovado, este é avaliado pela incorporadora, que analisa também a viabilidade da construção e o retorno financeiro, sendo estas informações passadas à construtora que fica responsável em dar prosseguimento ao processo, que tem início com a realização da contratação dos projetistas.

A empresa possui um cadastro com cinco escritórios de projetos, sendo efetuado o contrato por seleção restrita, conforme explicitado anteriormente. A empresa possui também uma ordem de prioridades, dando sempre preferência para o primeiro escritório do cadastro, uma vez que corresponde ao que obteve maior pontuação na avaliação da construtora. Somente a partir da negativa deste será procurado o escritório seguinte na lista, e assim sucessivamente.

A construtora possui uma tabela com índices para remuneração dos projetos que não são negociáveis.. O sistema de pagamento é feito em parcelas conforme o cronograma físico-financeiro, elaborado também pela construtora. Em cada etapa de entrega do projeto ficam retidos $5 \%$ do total do valor a ser pago ao projetista. Se o projetista cumprir a etapa seguinte no prazo e da forma como foi exigido em contrato, recebe os 5\% retidos na etapa anterior, caso ocorra atraso ou descumprimento de algum item, o escritório é multado em até $5 \%$. A multa é aplicada para que o erro não se repita. Como forma de incentivo, existe um prêmio que também poderá ser de até $5 \%$, podendo o projetista receber além dos $5 \%$ que haviam ficado retidos, $5 \%$ a mais se entregar a etapa em prazo inferior ao estabelecido no cronograma, ou se trouxer alguma sugestão que possa influenciar o 
preço final, ou, ainda, se apresentar proposta de melhor elaboração do projeto, enfim, se trouxer algum benefício à empresa, que não precisa ser necessariamente o lucro financeiro.

Nesta empresa, os projetistas são avaliados com notas que variam de 1 a 10. Essas notas determinam os valores das multas a serem pagas pelos projetistas, e dos prêmios a serem pagos pela construtora. Esta nota deve ser mantida em 7,5 para que não exista nem multa, nem prêmio. Caso esteja além de 7,5, a construtora pode pagar o prêmio de $1 \%, 2 \%$, até $5 \%$ e, caso esteja abaixo de 7,5 , a multa começará a ser cobrada dos projetistas, na mesma proporção. Se o escritório contratado obtiver nota 4,5 ou inferior, em qualquer etapa de entrega do projeto, o projetista é retirado do cadastro, estando impossibilidade de trabalhar para a construtora. Nesses casos é selecionado um novo escritório.

Segundo o entrevistado, gerente de projetos da empresa, esta forma de contratação e escolha do projetista tem a finalidade de garantir a qualidade do projeto e da construção. Segundo ele, é mais fácil encontrar escritórios de projeto com conhecimento técnico suficiente para desenvolver ótimos projetos em relação à funcionalidade e beleza, do que devidamente organizados para cumprir com todas as exigências da construtora no que se refere ao cumprimento dos prazos e qualidade dos serviços prestados.

\footnotetext{
"A nossa forma de contratação dos projetistas têm sido bem aceita pelos escritórios parceiros, pois acho que eles já se adaptaram aos nossos procedimentos e acabam satisfeitos com a possibilidade de prêmios. É um grande incentivo. $\mathrm{O}$ fato do preço ser pré-estabelecido não se apresenta como um problema porque pagamos bem pelos projetos. Como disse, passam a ser escritórios parceiros, que também não queremos perder porque sabemos que será difícil encontrar outro com as mesmas qualidades." (gerente de projetos).
}

A compatibilização e coordenação dos projetos são feitas pelo escritório que elabora o projeto executivo e tem também a função de passar o custo final do empreendimento. A gerência do projeto é feita pela própria construtora. Caso o custo do empreendimento esteja fora do valor estimado pela construtora, o projetista também perde pontos, podendo ser descadastrado, sendo contratado outro escritório.

Os projetistas de instalações e estruturas são contratados pelo escritório responsável pelo desenvolvimento do projeto executivo, assim este poderá escolher o melhor momento de contratação dos mesmos, sendo que se um deles atrasar a entrega de um projeto e comprometer a entrega dos demais projetistas, todos perderão pontos e poderão ser multados. O escritório responsável pelo projeto executivo passa a ser o responsável por toda a execução e compatibilização, sendo responsabilizado mesmo quando o problema ocorreu por algum atraso no desenvolvimento dos projetos das especialidades. A construtora não mantém sequer contato com os projetistas, sendo as reuniões feitas somente com o escritório responsável pelo projeto executivo. De acordo com o entrevistado, esta forma de atuação reduziu em muito o tempo das reuniões que existiam entre a construtora e os projetistas, além de evitar que um escritório responsável por um tipo de projeto procurasse a construtora para reclamar de problemas com outro escritório, o que trazia um desgaste das relações entre todos os envolvidos no processo, uma vez que o responsável pelo desenvolvimento do projeto definitivo, ou seja, o 
compatibilizador, não possuía autoridade para trocar projetistas, o que causou inúmeras vezes problemas ao processo.

A importância da confiança e responsabilidade creditada ao responsável pelo desenvolvimento do projeto executivo trouxe benefícios para as relações entre os profissionais envolvidos no processo de projeto, ocasionando melhoria na qualidade das inter-relações entre eles.

O Programa de Necessidades é definido pela incorporadora que, normalmente, já o entrega à construtora dizendo exatamente o deve ser considerado, e o retorno financeiro necessário. Estas definições de custos são discutidas durante o desenvolvimento mais detalhado do projeto, mas também não podem sofrer grandes modificações.

\section{Empresa E}

A empresa possui uma incorporadora vinculada à construtora que, como na empresa D, possui um quadro administrativo totalmente separado, funcionando como se fossem empresas distintas, mas que, na verdade, pertencem à mesma empresa. A incorporadora identifica os terrenos que interessam, e encaminha para a construtora que possui um setor de projetos próprio que desenvolve o estudo de viabilidade, cabendo à incorporadora a decisão sobre a compra ou não do terreno. Permanecendo o interesse da incorporadora no terreno, a construtora procura um escritório de projetos para desenvolver o estudo preliminar e o projeto legal. De acordo com o gerente de projetos da empresa, os escritórios são escolhidos dentre os que possuem arquitetos renomados no mercado, e admite que prefere que seja assim pois acredita que o nome do arquiteto funcionará como marketing de venda das unidades habitacionais. Após esta afirmação, o entrevistado avaliou a resposta dada e completou dizendo:

"se um arquiteto construiu uma história de sucesso e fez com que seu nome fosse reconhecido como bom profissional, significa que possui boa técnica e eficiência". (gerente de projetos)

A contratação deste profissional exige uma proposta técnica, que deverá ser apresentada por eles, juntamente com o cronograma físico-financeiro referente às entregas do projeto preliminar e do projeto legal. Depois o setor responsável pela coordenação de projetos da empresa decide quanto à melhor proposta para aquele empreendimento. Ressalte-se que a proposta escolhida não será necessariamente aquela que apresentou o menor preço, embora este fator influencie na contratação. $\mathrm{O}$ entrevistado exemplificou um empreendimento em andamento à época da entrevista, em que apenas um escritório se propôs a atender à expectativa de prazos que a incorporadora havia imposto, e, mesmo sendo o valor do projeto três vezes superior à concorrência, ele foi contratado por atender a outros requisitos valiosos na visão da empresa.

Percebeu-se no decorrer da entrevista uma grande preocupação com o custo e geração de lucro. Embora seja natural que qualquer empresa vise à obtenção de lucro, nesta foi vinculado o fator de redução de áreas das unidades e melhor interpretação das normas urbanísticas, conseguindo o melhor aproveitamento do terreno, como sendo uma grande prioridade para a contratação do arquiteto responsável pela concepção do empreendimento. 
Após a concepção realizada e o projeto aprovado pela Prefeitura do Rio de Janeiro, contrata-se a empresa responsável pelo desenvolvimento do projeto executivo. Essa contratação é feita por seleção restrita, na qual os escritórios encaminham seus currículos e propostas técnicas. Será contratado o escritório que apresentar a melhor proposta pelo menor preço. A experiência profissional dos escritórios é o fator mais considerado nesta etapa de contratação, uma vez que a empresa " $E$ " é recente neste setor da construção civil. De acordo com o entrevistado o ideal seria contratar profissionais com capacidade técnica e qualidade comprovadas em outros empreendimentos e empresas, para somar conhecimentos com esta empresa - que possuía equipe própria para a execução dos projetos comerciais. Os projetos das especialidades são contratados após a aprovação do projeto legal.

A compatibilização dos projetos é feita pelos profissionais do setor de projetos da empresa. Caso seja identificado algum problema na compatibilização, estes são encaminhados para os escritórios contratados com o intuito de serem resolvidos o mais rapidamente possível. Os prazos para o atendimento às modificações solicitadas durante o processo do compatibilização dos projetos são especificados em contrato, assim como a quantidade de vezes que se admite a realização de modificações. Quando estas modificações são necessárias por problemas durante a própria compatibilização, o escritório responsável pelo desenvolvimento do projeto executivo possui autoridade para estabelecer um limite de alterações, cabendo à empresa construtora o estabelecimento, em curto prazo, das necessidades de adequação dos projetos.

De acordo com o entrevistado, a compatibilização é a parte mais complexa do processo de projeto, pois existe a necessidade de integrar profissionais de áreas distintas, e os arquitetos renomados por vezes não admitem fazer modificações em seus projetos, acreditando que os demais projetos devem atender e se adequar ao projeto de arquitetura, ponto conflitante ao ponto de vista da empresa, que acredita que todos os profissionais precisam trabalhar conjuntamente.

Atualmente, existe a percepção da necessidade de se estabelecer um cadastro com escritórios que trabalham dentro da mesma filosofia da empresa, para dirimir os problemas existentes nas relações empresariais. $O$ entrevistado assegura que $o$ contrato bem definido e com clareza de informações impede o aparecimento de situações mais graves em relação ao processo de projeto, mas ainda assim, causa desgaste nas relações pessoais, que precisam estar sempre se reportando ao referido contrato para que este seja efetivamente cumprido.

\section{Empresa F}

Esta empresa possui setor de projetos próprio, mas também contrata os projetistas para todas as etapas do processo de projeto, sendo o setor interno responsável apenas pela compatibilização dos projetos.

A incorporação dos empreendimentos é feita por uma outra empresa, que contrata a construtora para a execução da obra. Esta incorporadora trabalha com outras empresas construtoras também, não sendo exclusiva da empresa " $\mathrm{F}$ ". As obras são contratadas e incorporadas de acordo com a qualificação técnica da construtora, sendo o estudo preliminar entregue pela própria incorporadora. Cabe à empresa " $\mathrm{F}$ " contratar os escritórios responsáveis pelas demais etapas do projeto e pelos projetos das especialidades. O resultado dessa forma de trabalho, é que, na maioria 
das vezes, a construtora e o projetista responsável pelo projeto legal, anteprojeto e projeto executivo não tem contato com o projetista que executou o estudo preliminar, existindo um problema na orientação das informações existentes neste estudo.

Cada etapa do projeto normalmente é contratada com o mesmo escritório para todos os empreendimentos. Cada escritório contratado é especialista numa determinada etapa de projeto, ou seja, existe um escritório com prática no desenvolvimento do projeto para aprovação na Prefeitura (projeto legal), outro que só desenvolve os projetos executivos, e assim sucessivamente, cabendo ao setor de projetos da construtora a escolha do escritório mais experiente em cada fase. Como a empresa " $\mathrm{F}$ " já se encontra no mercado há bastante tempo, foi criado um cadastro dos escritórios de arquitetura e detalhadas suas características técnicas, seus procedimentos em relação aos projetos, sua pontualidade na entrega dos mesmos, sua competência administrativa, entre outros fatores, e acabou-se por definir alguns escritórios que se tornaram "parceiros", sendo quase exclusivos da empresa. Este fato diminuiu os problemas ocasionados pela contratação de profissionais não qualificados, gerando grandes benefícios para a empresa construtora que, de acordo com o gerente do setor de projetos, passou a lucrar com os projetos, mesmo pagando mais por eles.

\section{RESUMO DAS ENTREVISTAS - PROPOSTAS PARA A CONTRATAÇÃO DE PROJETISTAS}

Todas as empresas consultadas trabalham com incorporadoras de forma separada da gerência de projetos e de obras. Mesmo quando a própria construtora também incorpora os empreendimentos, as funções de construção e incorporação são geridas de forma independente, funcionando como empresas diferenciadas.

De maneira geral, o programa de necessidades é fornecido pela incorporadora sem a consulta prévia ao profissional que executará a concepção do projeto e demais etapas deste, ocasionando problemas no momento de ajuste da demanda exigida pela incorporadora à realidade física do empreendimento.

Outro aspecto a ser ressaltado refere-se ao fato das empresas possuírem um cadastro de escritórios, que permite a realização de um contrato por seleção restrita. Em alguns casos o preço é pré-determinado, e em outros é feita a escolha do escritório pelo menor preço de projeto, mas sempre com a participação de 2 ou 3 escritórios de confiança das construtoras e incorporadoras. Esta prática tende a ocasionar uma demanda excessiva para alguns escritórios que passam a não conseguir atender aos pedidos e trabalhos contratados, restringindo a participação de novos escritórios, que poderiam se dedicar mais intensamente ao projeto por não terem tanta procura.

A contratação formal do projetista de arquitetura é feita somente para a realização do projeto legal. Até então, os projetistas executores dos estudos de viabilidade e concepção não possuem nenhum contrato e realizam estes estudos "no risco", visando a sua posterior contratação. Como não existe a certeza de serem contratados, muitos escritórios executam estudos para diversas construtoras ao mesmo tempo, não possuindo tempo hábil para a dedicação necessária a esta etapa tão valiosa tecnicamente, e que poderia garantir a qualidade da solução arquitetônica e da viabilidade construtiva. 
Os prazos exigidos pelas incorporadoras para as etapas de projeto são um fator comentado por todas as empresas entrevistadas, que avaliam serem estes prazos muito reduzidos e inadequados para o bom atendimento das expectativas dos engenheiros de obra, fazendo com que, em alguns casos, o projeto chegue incompleto.

O momento de contratação dos demais projetistas é outro problema identificado nas entrevistas. Embora as empresas não tenham analisado este fato como um problema, pois acabam resolvendo as dúvidas do projeto de arquitetura com consultas informais aos projetistas que serão contratados mais tarde, esta situação não pode ser entendida como a ideal. Entende-se que seria correta a contratação dos projetistas das especialidades juntamente com o projetista de arquitetura na etapa de concepção do projeto ou estudo preliminar, ainda que os projetos das especialidades somente precisassem ser apresentados em definitivo após a aceitação do projeto legal. Isto determinaria certo compromisso entre as decisões tomadas pelo arquiteto e as informações dadas pelos demais projetistas, com o registro dos gargalos identificados por toda a equipe de projeto, e dos motivos para a opção por uma alternativa em detrimento de outra.

O contrato existente entre as empresas construtora e incorporadora deve ser analisado sob o ponto de vista técnico. De acordo com a pesquisa efetuada, a incorporadora dita as regras de construção, apresentando seu programa de necessidades e o custo máximo que poderia chegar a construção do empreendimento, além de exigir o prazo para execução do mesmo. Este contrato visa o lucro da incorporadora que está associada aos valores de mercado e prazos de lançamento e venda das unidades habitacionais. No caso da construtora, seu lucro demanda em conseguir atender os interesses da incorporadora, para que continuem parceiros. Mesmo quando a construtora e incorporadora pertencem ao mesmo grupo empresarial, a cobrança por parte da incorporadora em relação aos custos previstos por ela e ao prazo exigido é feito de forma sistemática, muitas vezes reduzindo o prazo inicial dado de acordo com variações do mercado imobiliário, fazendo com que a empresa construtora (contratante dos projetistas) também reduza o prazo dos projetos e da obra.

Percebe-se que, na maioria das empresas, a compatibilização dos projetos é feita pela própria, nas que possuem departamento de projetos próprio, e a coordenação é feita por empresa contratada, geralmente a mesma que realiza o projeto executivo. Em nenhum caso foi relatada a exigência, em contrato, de visitas periódicas da firma coordenadora dos projetos ao canteiro de obras, sendo estas visitas feitas pela equipe de projetos da construtora, que repassa informações sobre os problemas encontrados, na execução da obra, relativos ao projeto. Seria oportuno inserir a importância das visitas à obra por parte da empresa executora do projeto executivo, mantendo contato direto com o engenheiro responsável pelo desenvolvimento da mesma, para que houvesse a troca de informações que traria maior envolvimento do projeto e sua execução.

\section{CONSIDERAÇÕES FINAIS}

A realização desta pesquisa permitiu identificar algumas das diferentes posturas adotadas pelas empresas construtoras que atuam no segmento residencial multifamiliar da Cidade do Rio de Janeiro. As considerações feitas pelos 
entrevistados permitiram estabelecer uma lista de recomendações para as construtoras e para os arquitetos, no sentido de buscar a forma de contratação mais eficiente.

De maneira geral é possível reforçar a importância de se identificar no contrato todas as obrigações do contratado e contratante, inclusive o cronograma físicofinanceiro das etapas de projeto e todas as informações que deverão estar contidas em cada etapa. Além disso, esse contrato deveria ser discutido antes da sua assinatura, para que ambas as partes pudessem exprimir suas opiniões e possibilidades para o cumprimento de suas obrigações, bem como medidas que pudessem beneficiar a gestão da realização do projeto. Entre as "obrigações dos projetistas", destaca-se a necessidade das visitas técnicas à obra, promovendo a interrelação entre o projeto e sua execução, com a conseqüente diminuição dos erros de projeto.

Pelos depoimentos coletados, percebe-se que a contratação dos projetos das especialidades deveria - sempre que possível - ocorrer no momento da contratação do projeto legal, o que garantiria a solução de questões técnicas antes que pudessem constituir um problema durante a compatibilização dos projetos

A discussão sobre o prazo ideal para a realização dos projetos ainda é matéria difícil de ser tratada, na medida que os incorporadores ainda não estão totalmente convencidos de que o investimento num projeto mais detalhado - e que portanto demanda um tempo maior para ser realizado - pode reduzir custos na obra com a eliminação (ou redução) do retrabalho e desperdícios na obra. Entretanto, pelas entrevistas realizadas, percebe-se certa sensibilização dos incorporadores para esta questão.

Finalmente, cabe destacar a importância das empresas de projeto e construtoras de entenderem o contrato como instrumento da visão interna da empresa, e não apenas uma forma de protesto judicial. Com esse objetivo é fundamental que se estabeleça, na fase anterior ao contrato dos projetistas, quais as demandas que são necessárias para a empresa construtora, que deverá diagnosticar sua prioridades contratuais sem ignorar as necessidades dos contratados para garantir a gestão da qualidade no processo de desenvolvimento do projeto e realização da obra.

\section{REFERÊNCIAS BIBLIOGRÁFICAS}

ASSOCIAÇÃO BRASILEIRA DOS ESCRITÓRIOS DE ARQUITETURA - ASBEA, Manual de Contratação dos Serviços de Arquitetura e Urbanismo, 2ed. São Paulo. Editora PINI, 2000.

CAIADO, V.N.S A contratação dos serviços de arquitetura e sua influência na qualidade do projeto: estudo de caso em construtoras do RJ. Dissertação (Mestrado) - Programa de Pós-Graduação em Arquitetura, Universidade Federal do Rio de Janeiro, Rio de Janeiro, 2004.

CASTELLS, E.J.F.; HEINECK, L.F.M. A aplicação dos conceitos de qualidade de projeto no processo de concepção arquitetônica - uma revisão crítica. In: WORKSHOP NACIONAL: gestão do processo de projeto na construção de edifícios, 1, 2001, São Carlos. Anais... São Carlos: EESC/USP, 2001. CD-ROM

FABRICIO, M. M. Projeto Simultâneo na Construção de Edifícios. Tese (Doutorado) - Escola Politécnica. Universidade de São Paulo, São Paulo, 2002 $308 p$. 
LANA, M. P. C. V.; ANDERY; P. R. P. . Integração projeto - produção: um novo paradigma cultural. In: WORKSHOP NACIONAL: gestão do processo de projeto na construção de edifícios, 1, 2001, São Carlos. Anais... São Carlos: EESC/USP, 2001. CD-ROM

LEI de Licitações, $\mathbf{n}^{\mathbf{0}} \mathbf{8 6 6 6}$ de 21 de junho de 1993.

MELHADO, S. B.: AQUINO, J. P. R. Perspectivas da utilização generalizada de projetos para produção na construção de edifícios. In: Gestão do processo de projeto na construção de edifícios. Anais. São Paulo. 2001.

SALGADO, M. S. Produção Arquitetônica e Interdisciplinaridade: uma discussão sobre o processo do projeto e a ISO 9001/2000. In: CONFERÊNCIA LATINOAMERICANA DE CONSTRUÇÃO SUSTENTÁVEL, 1 E ENCONTRO NACIONAL DE TECNOLOGIA DO AMBIENTE CONSTRUÍDO: MODERNIDADE E SUSTENTABILIDADE, 10, 2004, São Paulo. Anais... São Paulo: USP/ANTAC, 2004. CD-ROM

SOUZA, A.L.R., MELHADO, B.S. Preparação da Execução de Obras. São Paulo: O Nome da Rosa, 2003. 